\title{
A society ill-equipped to deal with the effects of climate change on cultural heritage and landscape: a qualitative assessment of planning practices in transport infrastructure
}

\author{
Hans Antonson ${ }^{1,2}$ (D) Philip Buckland ${ }^{3}$ (D) $\cdot$ Roger Nyqvist $^{3}$ \\ Received: 2 October 2020 / Accepted: 26 April 2021/Published online: 15 May 2021 \\ (C) The Author(s) 2021
}

\begin{abstract}
This paper provides insights into the handling of climate change issues related to cultural heritage at different government decision levels dealing with physical planning, and in particular roads. Data are derived from a qualitative analysis of official reports and interviews with local and regional planners in three Swedish regions with contrasting climates. The theoretical lens of Institutional Interplay is applied to an analysis grouped into six themes: Climate threats to cultural heritage, Adaptation measures, Preparedness, Institutional preconditions, Institutional interplay, and Challenges. The results suggest that despite a strong environmental reputation internationally, Sweden is not particularly well prepared for dealing with future climate change impacts on cultural heritage and landscape. The lack of national standards and standardised methods risks regional and sectoral variation in the treatment of similar tasks, a problem which deficiencies in knowledge and continuing education are perpetuating. The degree to which discussions and cooperation occur between divisions within the same authority, between authorities, and in national networks varies considerably. Routines and criteria for prioritisation of cultural heritage mitigation, essential under conditions of limited resources, have yet to have been implemented. We conclude with five recommendations for improving the planning process with respect to climate change risks to cultural heritage.
\end{abstract}

Keywords Adaptation $\cdot$ Cultural heritage and landscape $\cdot$ Roads $\cdot$ Cross-sectoral issue $\cdot$ Interviews - Government reports

Hans Antonson

Hans.antonson@kmvforum.se

1 KMV forum AB, Hästholmsvägen 28, SE-131 30 Nacka 8195 Linköping, Sweden

2 Department of Human Geography, Lund University, SE-223 62 Lund, Sweden

3 Environmental Archaeology Lab, Umeå University, SE-905 87 Umeå, Sweden 


\section{Introduction}

Cultural heritage $(\mathrm{CH})$ and landscape is highlighted as an important aspect of people's identity and well-being (Gifford 2014; Lewicka 2011). It is encompassed by both international agreements and national legislation, and must be considered in land use planning and construction, including transport infrastructure, by a range of stakeholders (Mézáros and Antonson 2020). There is extensive evidence of climate change threats to $\mathrm{CH}$ (e.g. Fatorić and Seekamp 2017; Sesana et al. 2018; Shirvani Dastgerdi et al. 2019). Despite this, CH receives little attention in IPCC reports (Kohler and Rockman 2020), and is generally expressed in terms of tourism when it does (Hall and Ram 2016). Moreover, measures for adapting $\mathrm{CH}$ and landscape to climate change are rarely found in the core research literature on climate change (Fatorić and Seekamp 2017; c.f. Fatorić and Biesbroek 2020), transport infrastructure or even $\mathrm{CH}$, and more research is called for (Sesana et al. 2018; Fatorić and Biesbroek 2020). More focus has been directed towards the preservation of archaeological sites and artefacts (e.g. Hollesen et al. 2019) and impacts on the built cultural environment (Bertolin, 2019), including the environmental implications of reusing historic buildings (Foster and Kreinin 2020). In a broader review of management strategies and policy-making for climate change and heritage, including landscape, Hall et al. (2016) conclude the need for a unified approach and that the field is underfunded.

Two years after the establishment of the Intergovernmental Panel on Climate Change (IPCC), Margaret Thatcher's (1990) speech on global warming at the second World Climate Conference, in Geneva, helped ensure climate change was transformed from a research and community issue to a highly political one. Sweden, as the first country to establish an environmental protection agency and host of the first United Nations Environment Programme (UNEP) climate conference, has been highly regarded internationally for its environmental engagement since the early 1970s. In 1998, the Swedish government decided to initiate a comprehensive climate strategy and action program, which emphasised cost-effective solutions for limiting and reducing carbon dioxide and other greenhouse gas emissions covered by the Kyoto Protocol (SOU 2000). Since 2005, a network of 17 government authorities and 21 county administrative boards, headed by the Swedish Meteorological and Hydrological Institute, has maintained an online platform for disseminating information on climate adaptation (www.klimatanpassning.se). This early start has undoubtedly helped Sweden become ranked second out of 162 OECD countries for the SGD13 Climate Action goal in the 2019 Global Sustainable Development Report (Sachs et al. 2019).

In a European perspective, transport infrastructure, and especially road transport, is directly associated with both climate change and $\mathrm{CH}$ : road transport is one of the largest contributors to greenhouse gasses (European Commission 2016) and roads often have immediately associated objects of cultural historical value. The latter are rare in the context we are using, and include, among others, historic buildings (stations, offices), milestones, living entities (old trees, treelined avenues, parks, endangered roadside flora), historic bridges, dry stone walls, old road railings and ancient monuments (e.g. rune stones or prehistoric grave mounds). Transport infrastructure planning is essential for the functioning of a modern society, and development and improvements, not least in connection with climate adaptation, occur continually. Improvements often conflict with heritage conservation legislation, which adds an additional level of complexity to an already complex planning process to take account of bearing capacity, traffic flows, drainage, etc. As longitudinal objects networking almost all countries, roads are a significant component of the human and natural landscape. Just as climate change 
requires interdisciplinary research (Fatorić and Seekamp 2017), transport infrastructure is a cross-cutting research and planning issue that cannot be treated sectorally (Antonson et al. 2016; Mézáros and Antonson 2020; Sandkjaer Hanssen et al. 2013). The planning, construction, operation and maintenance of transport infrastructure involve not only several legislations but also many stakeholders, including authorities, companies, NGOs (non-governmental organisations) and the public (Mees et al. 2013). Interaction within and between these actors may usefully be explored using Young's (2002) 'Institutional Interplay'.

This paper helps fill a research gap regarding the effects of climate change on $\mathrm{CH}$ and landscape, and how it is handled by different levels of government. A qualitative analysis is applied to data relating to roads in Sweden, and the results compared with the state of knowledge in research literature. We believe that insights from this study will help in improving the planning process internationally.

The study was undertaken through a systematic review of official reports and interviews with local and regional planners in three Swedish regions (Fig. 1). The analysis was guided by the following research questions, whilst focusing on roads:

1. What climate threats to, and adaptation measures for, $\mathrm{CH}$ and landscape are government authorities actively working on?

2. What strategies are being developed to handle climate change considerations in planning practice?

3. How is climate-related work undertaken in practice within and between organisations, and in what way do the planners' preconditions facilitate or hinder work specifically relating to climate change effects on $\mathrm{CH}$ and landscape?

The paper is structured as follows: First, we review the complex structure of Swedish governance in relation to $\mathrm{CH}$, transport infrastructure and climate change. Section 3 presents institutional interplay as a theoretical framework, and Section 4 describes the case study areas, methods, source material and analytical tools. Section 5 presents the results grouped into six themes, which are analysed and discussed in relation to international research in Section 6 and used to draw conclusions in Section 7.

\section{Roads, climate change and heritage governance in Sweden}

Until 2013, construction and maintenance of roads was managed by a single actor, the Swedish Road Administration (SRA), which planned, expedited, acquired land and built new roads with little room for involvement by others. If any protected monuments or sites (nature conservation or $\mathrm{CH}$ ) were affected, a regional authority, the County Administrative Board (CAB), was engaged, and archaeological excavations could legally be required. After Sweden joined the European Union in 1995, all EU environmental legislation become mandatory. The Swedish Environmental Code was subsequently introduced in 1999, putting a greater focus on participatory procedures (public, NGOs, municipalities, enterprises) and into which some of the EU's directive were transposed. Concurrently, environmental consultancies emerged to undertake an increasingly large part of the SRA's previously in-house tasks. In 2013, the SRA was merged with the Swedish Rail Administration to form the Swedish Transport Administration (STA). 


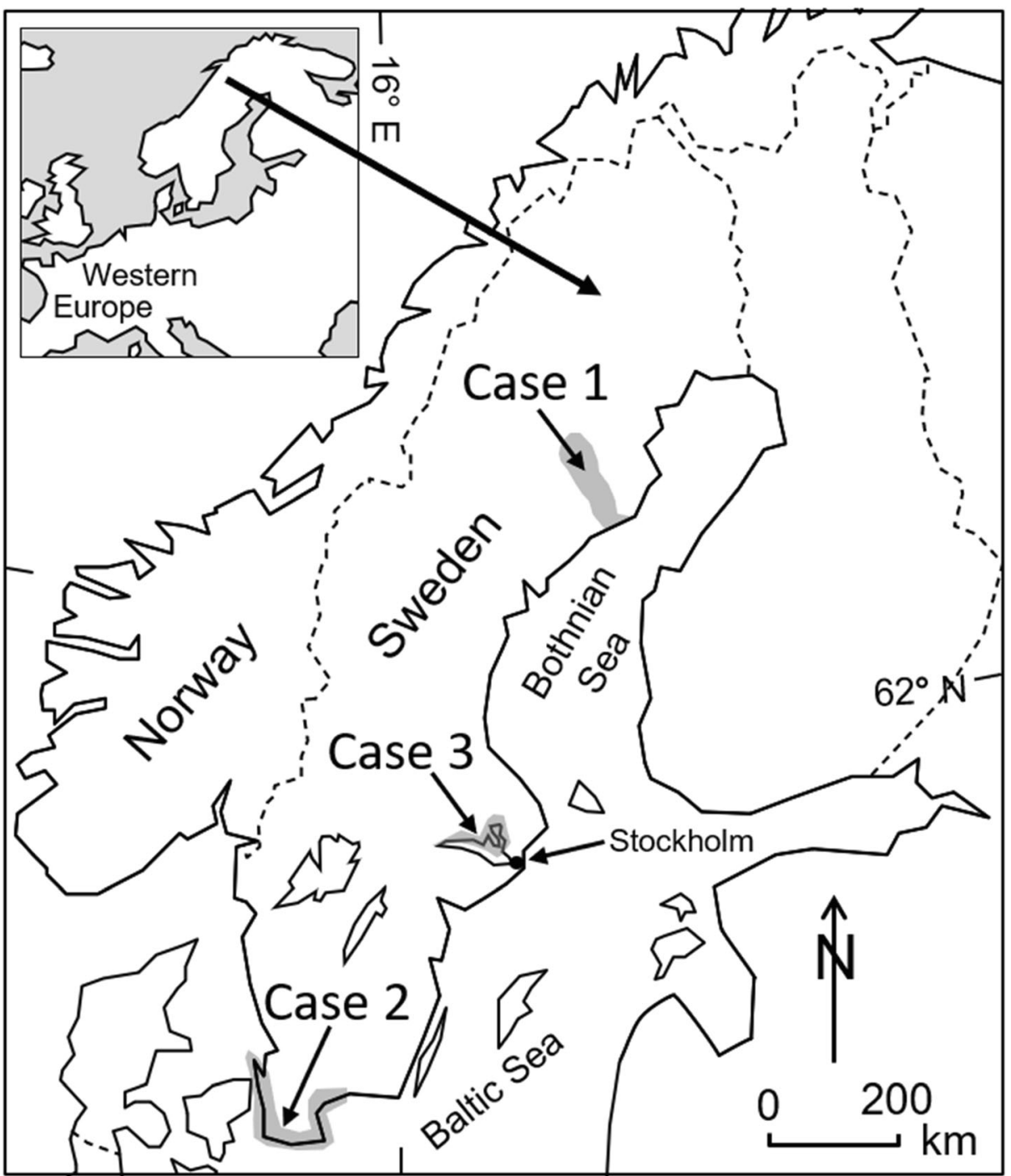

Fig. 1 The three (grey shaded) case study areas: (1) the Vindel-Umea river valleys, (2) the Scanian coast and (3) the area north of Lake Mälaren

Central government legislations and supranational agreements direct the actions of the CABs at the regional level; the most important of these are the Swedish Historic Environment Act (ancient monuments), Swedish Roads Act (maintenance of old and building of new roads), European Landscape Convention and the European Climate Directive. The National Heritage Board (NHB), Swedish Environmental Protection Agency and the Swedish Meteorological and Hydrological Institute are responsible for advising on or enforcing parts of these directives. The $21 \mathrm{CABs}$ oversee all regional land use ( $\mathrm{CH}$ included) issues in conjunction with development. Regions are divided into municipalities, the local levels, which have the authority to manage the majority of other land use issues within their boundaries. The interest organisation for Sweden's 290 municipalities (Swedish Association of Local Authorities and 
Regions) has not yet produced any joint municipal adaptation policy, although two reports (Sveriges kommuner och landsting, 2015a, 2015b) have been produced with examples of good practice for assessing climate risks and adaptation in conjunction with construction.

The STA is a decentralised national authority with regional offices responsible for $\mathrm{CH}$ within their geographical area. These offices manage both new investment and remodelling and maintenance of existing transport infrastructure. Regional offices host a variety of experts, including those for climate and $\mathrm{CH}$ respectively.

In 2009 and 2013, the Swedish government instructed the CABs to map regional needs for adaptation to climate change. One year later, the STA (2014) published their first climate adaptation strategy. Sweden adopted its national strategy for climate adaptation in 2018 (Government 2018). CH is mentioned either very briefly or not at all in any of these documents.

\section{Theoretical framework}

Young (2002) highlights the importance of a well-functioning institutional interplay, and provides a framework for interpreting complex planning situations. This is highly relevant to the situation described above, where numerous actors are involved, in connection with land use, in the management of cultural heritage and landscapes. For any given issue, the interplay operates both within each authority sector and between authorities from different administrative decision-making levels. Interplay largely revolves around barriers that may hinder smooth planning practice, including conflicts, procedures and participation. These interact with the preconditions of ground-level bureaucrats (Lipsky 1980), including mandate (Antonson et al. 2016), knowledge (Corfee-Morlot et al. 2011), roles (Storbjörk 2007), negotiations (Mézáros and Antonson 2020), regulations (Bedsworth and Hanak 2013), poor routines (Uittenbroek 2016) and resources such as funding and staff (Bedsworth and Hanak 2013; Ziervogel and Parnell 2014). Comprehensive networks (Antonson and Carlson 2018) and the fostering of shared knowledge (Berkes 2009) have also been highlighted as phenomena that facilitate good planning practice.

\section{Methods and sources}

This study has used two methods, digital document search and semi-structured in-depth interviews, as well as two source materials, official reports and interview transcripts, which are analysed through content analysis. These are all described below after a description of the case study areas.

Three case study areas were selected in advance (Fig. 1, Appendix 1), distributed from South to North in Sweden and covering a range of landscape types, climate and vegetation zones. The aim was to obtain a wide national representation, rather than compare and contrast the individual areas.

Seventy-six national reports were collected, and 19 semi-structured in-depth interviews (Kvale, 2007; Baxter and Eyles 1997) were undertaken with 21 interviewees. Data collation followed a stepwise process, starting with the official reports. Official reports were gathered by searching Google and Google Scholar using a combination of 12 Swedish keywords (Table 1), between 14-02-2019 and 07-03-2019. The documents originate from a number of different 
authorities, including government ministries, County Administrative Boards (CAB) and the Swedish Transport Administration (STA). Appendix 2 lists the publications used in this study. The words "transport infrastructure" and "road" were excluded as search terms as they prohibitively limited the search results.

The second step was to undertake interviews, using the official reports as a point of departure. Information from the reports helped formulate interview questions, but also helped prepare the interviewer for asking follow-up questions based on the interviewees' assumed knowledge of the reports. Follow-up questions, outside a predefined interview guide, are essential in the context of a semi-structured in-depth interview, and may capture detail which would otherwise be missed. Interviewees consisted of government officials from local and regional levels working in or with $\mathrm{CH}$, transport infrastructure and climate adaptation, or any combination of these. Relevant individuals were identified through telephone contact with the municipalities, CAB and STA offices located in each of the three case study areas. A snowball procedure, where the primary contacts were asked to suggest additional participants, led to the identification of additional interviewees. One civil servant was interviewed from each geographical area and within each authority. These individuals cover the minimum set of competencies relevant for this investigation, and are considered sufficient to reflect the routines and values inherent in each institution. The study thus follows established precedence for the use of qualitative analysis (e.g. Kvale 1994; Creswell 2014; Robinson 2014), where the quantity is not decisive, but rather the substantive reasoning.

Initial contact with interviewees was by phone or email. Interviews were based on an interview guide devised by this research team, and consisting of 40 questions arranged into six groups (Table 2), and which the interviewees were not permitted to see prior to the interview. The lead author conducted all 19 interviews (Table 3) at the respective respondent's workplace (16), via Skype (2) or at a café (1) in June, October and November 2019. The median length of interview was $58 \mathrm{~min}$, and ranged between 32 and $82 \mathrm{~min}$. Interviews were recorded, then transcribed by a professional transcription consultant. Respondents were not permitted to see the analysis prior to publication.

The official report texts and interview transcripts were processed using content analysis, resulting in a number of themes used to structure the analysis presented below (following Bryman and Teevan 2005). These themes overlap with, but do not necessarily duplicate the groups into which the interview guide was arranged (see Table 2), the latter being based only on the content of the reports.

Table 1 Search terms used to find reports. Swedish original and English translation

\begin{tabular}{ll}
\hline Swedish & English \\
\hline Klimat & Climate \\
Klimatförändring & Climate change \\
Översvämning & Flood \\
Nederbörd & Precipitation \\
Frost & Frost \\
Värme & Heat \\
Bränder & Fires \\
Kultur & Culture \\
Kulturmiljö & Cultural environment \\
Kulturarv & CH \\
Landskap & Landscape \\
Skada & Damage \\
\hline
\end{tabular}


Table 2 The six groups into which the 40 questions used in the interviews were organised

Climate-related issues relating to cultural environment, cultural historical objects and landscapes

Responsibility and the organisation's procedures

The impact of climate change on cultural environments, cultural historical objects and landscapes connected with transport infrastructure

Adaptation measures to protect and preserve the cultural environment and landscape for the future

Knowledge and competence

Challenges and needs

\section{Results}

The results of the analysis of official reports and interviews are provided below, according to the six themes identified. Quotes are provided from translated interview transcriptions and report texts to illustrate points and clarifying details. Almost none of the reports, and few of the interviewees, explicitly discussed an integrated concept of $\mathrm{CH}$ and landscape, and the reporting of our results thus reflects this omission through the use of the (arguably) narrower concept of $\mathrm{CH}$.

\subsection{Climate threats to cultural heritage}

The degree to which the reports deal with the impact of climate change on $\mathrm{CH}$ varies considerably, from comprehensive discussion of specific issues to only mentioning problems in passing. The Nordic Council of Ministers collaborative program for environment and climate only states that " $\mathrm{CH}$ and cultural landscapes are exposed to threats of environmental pollution and climate change" [1].

Table 3 Interviewees and their case study areas. $C A B$, County Administrative Board - regional level; STA, Swedish Traffic Administration. Municipalities reflect the local level. Case numbering, see text, first paragraph

\begin{tabular}{|c|c|c|c|}
\hline \multicolumn{2}{|l|}{ Respondent code } & \multirow{2}{*}{$\frac{\text { Organisation }}{\text { CAB }}$} & \multirow{2}{*}{$\frac{\text { Case }}{1}$} \\
\hline A & & & \\
\hline B & Interviewed in tandem & $\mathrm{CAB}$ & 1 \\
\hline $\mathrm{C}$ & Interviewed in tandem & $\mathrm{CAB}$ & 1 \\
\hline $\mathrm{D}$ & & Municipality & 1 \\
\hline $\mathrm{E}$ & & Municipality & 1 \\
\hline $\mathrm{F}$ & & STA & 1 \\
\hline G & & STA & 1 \\
\hline $\mathrm{H}$ & & $\mathrm{CAB}$ & 2 \\
\hline I & & $\mathrm{CAB}$ & 2 \\
\hline $\mathrm{J}$ & & STA & 2 \\
\hline $\mathrm{K}$ & & STA & 2 \\
\hline $\mathrm{L}$ & & STA & 2 \\
\hline M & Interviewed in tandem & Municipality & 2 \\
\hline $\mathrm{N}$ & Interviewed in tandem & Municipality & 2 \\
\hline $\mathrm{O}$ & & Municipality & 2 \\
\hline $\mathrm{P}$ & & $\mathrm{CAB}$ & 3 \\
\hline Q & & $\mathrm{CAB}$ & 3 \\
\hline $\mathrm{R}$ & & Municipality & 3 \\
\hline $\mathrm{S}$ & & Municipality & 3 \\
\hline $\mathrm{T}$ & & STA & 3 \\
\hline $\mathrm{U}$ & & STA & 3 \\
\hline
\end{tabular}


The NHB's detailed description of climate-related threats to $\mathrm{CH}$ [2] describes a chain of events from a specific aspect of climate change (e.g. increased precipitation), its consequent impacts (e.g. landslides), how it affects $\mathrm{CH}$ (e.g. collapsed structures) and what adaptation measures are required (e.g. increased storm drain and culvert dimensions). Threats to $\mathrm{CH}$ are grouped into six themes: landslides; floods; extreme rainfall; increased moisture (warmer air); rainier winters; pests, mould and fungus. A report from Umeå University and Västerbotten CAB [3] highlights five types of threat and provides examples of effects: higher temperatures (altered soil moisture leading to damaged buildings organic degradation), erosion (crushing ice masses), storms (windfalls), overgrowth, outcompeting vegetation (invasive species). This report is one of the few official publications to explicitly include a landscape perspective. A number of interviewees from the north highlighted threatened Sami heritage "The overgrowth of Sami heritage sites is clear [...] when the visible heritage disappears" (respondent C). Furthermore, the government's Climate and Vulnerability green book [4] highlights the importance of cultural identity.

The Swedish Civil Contingencies Agency studied flood records over a 100-year period and identified damage to collections in museums and archives, a risk that is predicted to increase in the future [5]. In Kronoberg County, Storm Gudrun damaged over 3200 of more than 11,000 ancient monuments in 2005, damage which has been attributed to climate change [6]. Whilst the direct effects of storms on forestry are often the focus for reports, the Swedish Forest Agency also highlights consideration of the potential effects of adapting timber transportation to climate change in its action plan for increased climate adaptation [7]. If other routes are needed, with poor ground conditions for heavy machinery, damage may be caused to "land, water and CH remains".

A varied picture emerges from the interviews, suggesting that most authorities have barely begun to work with climate-related threats to $\mathrm{CH}$. This is summed up succinctly by an STA official as "at the moment nothing really. We are trying to understand the situation when developing new plans or investigations" (respondent T). However, a number of the interviewees have begun to reflect on the threats and what $\mathrm{CH}$ may be threatened. A STA interviewee stated that "if I get to choose one [threat], it is water and increased levels. Heavy rainfall makes the roads or drainage culverts insufficient to cope with floods, resulting in disappearance of both the road and railroad. It is urgent. [But also] heat and drought" (respondent T). The interviewees also consider storminess a threat outside of forestry, causing "increased [coastal] erosion. High sea level combined with strong currents caused major effects in the 2013 storm Sven" (respondent H).

The reports' aggregated picture of the affected $\mathrm{CH}$ is corroborated by the interviewees, although few reports provided a comprehensive overview of each problem. The interviews complemented the reports, however, highlighting organisational awareness of the threatened $\mathrm{CH}$ of transport infrastructure. According to most interviewees, water, in one form or another, is the greatest climate threat, a view reflecting the current focus of Swedish organisations which have started working with climate change and heritage.

The interviewees also demonstrate awareness of more indirect factors, and potential effects on organic materials. These include invasive species, as "with the heat comes perhaps insects previously not present that [also] attack healthy wood" (respondent B). "The shipworm does not thrive if it's below 12 degrees at the [sea] bottom. But it's entering [our region] and is already found in the South Baltic, especially alongside the German coast. We will lose much cultural history if it enters [the Swedish territory]" (respondent I). Whilst higher temperatures 
are generally associated with higher humidity in Sweden, and thus organic decay, they are also associated with increased risk of forest fires, and "what burns up is gone" (respondent D).

At least one interviewee was aware of the risk climate change poses to archaeology preserved under ice and snow, and stated that the loss of "permafrost, [...] glaciers melt away, maybe artefacts that we did not know about will be exposed and damaged before finding them" (respondent A).

A compilation of the reports and interviews resulted in a list of climate change expressions and direct and indirect impacts on $\mathrm{CH}$ (Fig. 2).

\subsection{Adaptation measures}

The Swedish Government's National Strategy for Climate Adaptation [8] states that work on $\mathrm{CH}$ climate adaptation should take place at the local level (municipalities), but that few tangible measures have been implemented. The studied reports indicate that more adaptation work is undertaken at the regional level (via the CABs), and that most of this is preparatory in nature (e.g. risk and vulnerability assessment, development of methods and tools for managing climate change impacts). Nevertheless, some targeted measures have been implemented, often through $\mathrm{CAB}$ initiatives.

Work on $\mathrm{CH}$ adaptation measures appears to be progressing at different paces within different sectors. According to several interviewees, it is rare for adaptation measures to be initiated in the $\mathrm{CH}$ sector per se; more often than not, they are the indirect consequences of other planning measures. "I know that STA and the municipalities [...] enlarge culvert dimensions. It is done to cope with the climate effects. You might protect [the $\mathrm{CH}$ ] even though that is not the primary purpose" (respondent A). However, one interviewee proposed a more holistic view, suggesting that "we are now in a tentative stage [of] what to do, what is required by us before future planning. How to get climate change adaptation

\begin{tabular}{|c|c|}
\hline $\begin{array}{l}\text { 1) Climate change expression } \\
\text { - Increasing temperature and heatwaves } \\
\text { - Increasing precipitation } \\
\text { - More storms } \\
\text { More freeze-thaw events }\end{array}$ & $\begin{array}{l}\text { 3) Primary impacts on } \mathbf{C H} \text { and landscape } \\
\text { - Crushing damage through external pressure } \\
\text { - Cultivated plants outcompeted by other species due to heat, water, cold } \\
\text { - Cultural landscapes (biotopes) such as wet meadows (these seasonally flood } \\
\text { normally) that will be permanently flooded }\end{array}$ \\
\hline $\begin{array}{l}\text { 2) Changed environmental circumstances } \\
\text { - Geohydrological changes affecting ground stability (landslides, } \\
\text { erosion, subsidence) } \\
\text { - } \frac{\text { Reduced permafrost affecting ground stability (subsidence) }}{\text { Unbalance in seasonal frozen ground, resulting from more freeze- }} \\
\text { thaw events, and leading to increased surface water } \\
\text { - Termanent sea-level rise due to melting glaciers } \\
\text { - Increased water flow causing flooding, undermining and pressure } \\
\text { - Increage } \\
\text { - Dryer forests } \\
\text { - Shifted vegetation periods }\end{array}$ & $\begin{array}{l}\text { - Switching of crops to energy forests, changing the traditional farming } \\
\text { - Dandscape } \\
\text { - namage to archaeological sites on change of land-use (e.g. forests and } \\
\text { - More difficult to identify archaeological sites due to regrowth } \\
\text { - Fire damage to artefacts and structures underground } \\
\text { - Easier to locate archaeological finds after vegetation has burnt } \\
\text { - Damage to artefacts and palaeoenvironmental data (e.g. fossil pollen and } \\
\text { insects) in wetlands which dry out } \\
\text { - Damage to archaeological sites when trees are up-rooted due to increased } \\
\text { demand for biomass for renewable energy } \\
\text { - Decreased grazing pressure from reindeer in mountain regions as a result of } \\
\text { increased insect pests in a warmer climate }\end{array}$ \\
\hline $\begin{array}{l}\text { 4) Secondary impacts on } \mathrm{CH} \text { and landscape } \\
\text { - Altered experience of a visually changed landscape, and thus } \\
\text { cultural identity, through a longer growth season } \\
\text { - Damage to (semi-nomadic) Sámi culture resulting from poorer } \\
\text { winter reindeer grazing, as more freeze-thaw events create thicker } \\
\text { ice crusts on snow } \\
\text { - Corrosion damage to metals through increased winter road salt due } \\
\text { to more freeze-thaw events } \\
\text { - Damage to archaeological sites in forests in connection to machine } \\
\text { extraction of wood }\end{array}$ & $\begin{array}{l}\text { surface water and humidity } \\
\text { - Pests attacking cultivated plants and wooden constructions } \\
\text { Damage/washing away of } \mathrm{CH} \text { (roads, bridges, road terraces, archaeological } \\
\text { - sites) with floods, landslides and (coastal) erosion } \\
\text { Reduction in damage to roads from freeze-thaw and deformation with } \\
\text { increased temperatures and reduced depth of seasonal frozen ground } \\
\text { The CH and agricultural landscape of the archipelago can be damaged by } \\
\text { wind farms } \\
\text { - Subsidence in structures due to changed ground water (drought, increased } \\
\text { rainfall) } \\
\text { - Ingress of water into buildings in exposed locations }\end{array}$ \\
\hline
\end{tabular}

Fig. 2 Climate threats and impacts on $\mathrm{CH}$ and landscape mentioned in Swedish official reports and interviews. Circumstances and impacts with connections to transport infrastructure are underlined 
[of $\mathrm{CH}$ ] as a part of the whole [process], as opposed to something on the side [of other activities]" (respondent T).

Extreme heat was of particular concern to one interviewee, "we had many unhealthy [treelined] avenues [last year]. On [the island of] Öland, a great many died that we replanted. [...] If it gets very hot then there will be a struggle to keep the avenues alive" (respondent L). Other vegetation concerns, beyond transport infrastructure, are expressed in the reports. This includes awareness of the need for preparation for changing cultivation conditions in agriculture, where a "greater variety of crops that are better adapted locally" [7] could be regarded as an implicit $\mathrm{CH}$ link to older crop varieties. Adaptation measures, in the form of larger drainage dimensions, however, "may cause greater damage to ancient remains in arable land" [7]. These insights into rural areas are rare in the interview responses, which often focus on urban areas, residential housing and other buildings: "our art museum is located at street level [...] flood mapping shows that the street outside can be affected by substantial water flows. We have undertaken simple measures by simply raising the storehouses 30 centimetres above the floor level, then we can handle everything" (respondent R). Another interviewee mentioned "groundwater management, delay systems and so on. [...] Yes, groundwater needs to be pumped away" (respondent $\mathrm{O}$ ). This interviewee also acknowledged that not everything can be protected "it's a balancing act, [...] to protect but partly also to drop some areas, [...] an organised retreat".

\subsection{Preparedness}

The reports rarely discuss society's readiness to meet the future, mostly describing theoretical aspects of planning for coping with future climate change. The Swedish Civil Contingencies Agency understands that collections in museums and archives, for example, "must be protected from water and moisture" [5]. The Swedish Meteorological and Hydrological Institute provides suggestions for developing guidelines on how $\mathrm{CH}$ should be integrated into other areas of society, national guidelines for monetary valuation, tools for care and maintenance planning and methods for risk assessment [9]. The same report highlights the importance of "including information on $\mathrm{CH}$ in tools and other authorities' work on climate change, such as the CAB's climate adaptation plans and risk and vulnerability analysis".

The interviews provide a clearer picture of the extent of practical activities, giving an overall impression that thinking or working with $\mathrm{CH}$ in conjunction with climate change has not yet been considered at more than a general level. One CAB official states that "first I want to say that it is not until now that we have thought that $\mathrm{CH}$ and climate adaptation are related. [...] I must be humble and say that this is an area where we have not worked with any welldeveloped systematics. We still have more to do here, absolutely. Other climate-related risks, however, are dealt [with]" (respondent $\mathrm{P}$ ). The interviewees describe different forms of $\mathrm{CH}$ strategy programs at the respective authorities, but these were created before climate threats were considered. This suggests that authorities generally lack a vital knowledge base that would indicate a degree of preparedness. $\mathrm{CAB}$ interviewee respondent I was particularly forthright and critical about how the $\mathrm{CH}$ sector handles climate issues, "we have no preparedness for this in Sweden. Who should handle this? The National Heritage Board has dismantled itself and all the rest are commercial enterprises, and who pays and so on? There is no defined system to quickly document things that are being destroyed. That's a problem". Of the 21 interviewees, only one respondent (L) considered the division of responsibilities and roles as being clear. 
It is evident that $\mathrm{CH}$ is not a primary consideration where the societal aspects of climate change adaptation are concerned. This is made apparent by a number of the interviewees: "I haven't thought much about that. So, it is not a question often communicated by us here in [municipality name], so there is probably very little focus on it" (respondent $\mathrm{O}$ ). Where land use and transport infrastructure are concerned, priority is given to concerns more generally recognised in the public eye, such as housing, development, road safety and accessibility. Respondent G comments that "I still believe that in the vast majority of priorities, if prioritization is not being done properly, then [culture] comes at the bottom of the priority list [...] and we have to change that". A STA officer remarks in frustration that "I am self-taught in climate adaptation, though assisted by colleagues and thus have [tried] to form my own idea of what we should focus on at the regional level. [...] A lot depends on me as an individual. [...] It's all about my own interest" (respondent T).

\subsection{Institutional preconditions}

The three interviewed authority types are subject to various legislations governing their actions to varying extents. This plethora of steering documents was seen by several interviewees as problematic with respect to climate change and $\mathrm{CH}$ activities, and according to one $\mathrm{CAB}$ officer, “... it is a bit too fragmented and unclear" (respondent D). More detail was provided by another expert, in that "because the mandate is so weak maybe some legislative changes are needed concerning some issues. There are so many different interests and laws that [counteract each other]" (respondent Q). A degree of uncertainty is expressed on how far the responsibilities of the various authorities extend, as exemplified by one of the interviewees, "Regarding the Flood Directive, I have asked myself how far our line of responsibility extends? I can't see that [the STA] can drop [the responsibility] just where our right of way ends" (respondent F). The perceived lack of clarity in regulation is discussed below in terms of institutional interaction routines between and within the authorities (see Section 5.5).

In contrast, some interviewees felt that the control documents were sufficiently clear. "It is present in the $[\mathrm{CAB}]$ appropriation letter and administrative instruction letter [from the government]. Then it can come [in] from the side, that we're being assigned a task or something. The latest is called the Climate Adaptation Ordinance which for the CAB is just a supplement or clarification to what we have been doing for almost 10 years, but now [we] are expected to adapt our own organisation. In the past, focus on the environment was outside the CAB. This regulation also applies to many other authorities, a total of about 40 , including the STA. Ergo, there we are, so, if not before, now it is clear that we also must look into the issue called CH" (respondent P).

Many of the interviewees feel that they neither have the time nor resources for adequate preparation. According to $\mathrm{CAB}$ officer respondent $\mathrm{B}$, "we mostly work reactively, pretty much guided by the cases that come in; that we primarily work with these. These types of development issues always come afterwards and may be difficult to keep up with". Respondent $\mathrm{D}$ elaborates, "our area of responsibility is the $\mathrm{CH}$ of our county. [...] One single [employee] has basic funding, and the rest is entirely dependent on the assignments we get. [...] [Climate change work linked to $\mathrm{CH}$ is undertaken on] our own initiative and is [based on] our own experiences, in some way what we see is happening" (respondent D). According to respondent $\mathrm{A}$, a $\mathrm{CAB}$ officer, "[this is dependent on] whether a person has time and resources, and perhaps also an interest in working with the issue, because it is a branch [with] rather scarce resources, and then climate adaptation [for heritage] suffers. [...] But we have seen this 
in all areas, that [the climate issue] enters and [later] becomes natural in the work. I suspect it will probably be the same for $\mathrm{CH}$, but we are not quite there yet".

Sufficient knowledge is a basic prerequisite for being able to perform climate-related tasks. The interviews give the impression of significant differences in the levels of knowledge between organisations, and few of those interviewed felt that they were sufficiently familiar with the subject. "The problem with my education is that it can get pretty out of date quickly. It's more about trying to keep up with climate research" (respondent A). Respondents remarked on the lack of time available for continuing education whereas a CAB officer commented that "you are not able to keep up with the material being produced $[. .$.$] because$ you always have, yes, urgent assignments [to] work with. It is almost in your spare time that you get to read these reports" (respondent H). Despite the fact that there are budgeted training days at each authority, employees do not seem to feel they always have the time to participate.

Where time is available, knowledge is acquired through scientific literature, or summaries of these at the Swedish Portal for Climate Adaptation (SMHI 2020), university courses outside of work hours, seminars, conferences and handbooks. Most respondents were aware of the availability of written guidance, and that there exist disparities in the extent of knowledge between divisions of the same authority. From the $\mathrm{CH}$ perspective, "[t]here is a climate coordinator at the $\mathrm{CAB}$ and a small group of people working on these issues from different points of view. [...] We, at $\mathrm{CH}$, have certainly arrived late in the work, e.g. but ecologists and others have been doing this for a few years" (respondent I). One CAB interviewee explained the need for coordination, "there are $21 \mathrm{CABs}$, each one a freestanding authority. There may be the need to produce [a] guide [...] to ensure that we work somewhat similarly. [...] Regarding climate adaptation, we have read a very good guide developed by the Royal Institute of Technology" (respondent P). A municipal planner, on the other hand, comments that "when it comes to culture, there are [...] materials that we get from the National Heritage Board, their handbooks, etc. It is usually not constructive when it comes to climate impact, that I can say" (respondent E).

There currently appears to be little strategic planning in climate adaptation work at these authorities. In the opinion of one strategic STA officer, "maybe we should work more proactively on all issues, but we are not really there as an organisation. [...] We put out fires instead of being there beforehand" (respondent T). A more hands-on officer reinforces this perspective, "at present, [...] we have mainly worked a bit ad-hoc where the problems occur. But that is what we want to move away from, and become more strategic in the future" (respondent K). This is in line with the local level in which one municipal planner states that, "no, there are no specific routines for how to work on the climate issue." (respondent N). A strategically driven agency should have a plan for what to begin with and what can be put on hold. The interviews reveal a frustration about difficulties regarding the latter, and the need to "in some way be able to prioritise. [...] What is the most urgent, what is [the greatest] need to be addressed in such cases?" (respondent U).

Whilst the interviews give the impression of authorities poorly prepared for making decisions on managing $\mathrm{CH}$ with respect to climate change and transport infrastructure, this is not the same as inactivity. The authorities have come further in other areas with direct or indirect implications for $\mathrm{CH}$. This includes following a government directive to undertake flood and precipitation mapping, which is undertaken, in some cases, with attention to $\mathrm{CH}$. Most of the organisations use Geographical Information Systems (GIS) for studying threats, risks and vulnerability, most commonly mapping possible future rainfall and flood events. According to one CAB planner, they are "using simpler GIS analysis. [...] Maybe 
analysis is too powerful a word. [...] We have used layers for ancient monuments and protected buildings respectively and have combined the two layers with, what we judge as climate-related risks [such as] natural risks, rainfall, landslide risks, erosion and watercourse flooding" (respondent P). In contrast, a municipal respondent explains that "we have not yet arrived there. We have begun trying to identify, but we have not yet used any tools or methods" (respondent D).

\subsection{Institutional interplay}

At Swedish authorities, cross-cutting issues which affect many areas tend to be handled by designated units. Climate, along with nature, $\mathrm{CH}$, energy and transport, is no exception. Most of the interviewees were well-educated experts in $\mathrm{CH}$ or transport infrastructure, but previous education in climate change and adaptation was unusual. Conversely, an interviewee educated in climate issues was not particularly familiar with $\mathrm{CH}$ issues, illustrating the need for interaction between different areas of expertise when managing climate and culture. When making decisions within the same unit, it is common for employees to seek support from colleagues, a function generally considered well-functioning and important in the studied authorities. Cooperation between different units within the same authority, on the other hand, cannot be considered functioning well enough. A number of CAB and STA staff highlight a lack of interaction, in that "we, [at the $\mathrm{CH}$ unit] very rarely remit to other [units], rather we respond to remits from other units in-house" (respondent B). In-house interplay is a matter of who has the mandate, or whether the mandate is experienced as outside of everyone's responsibility. The latter was experienced by several of those interviewed, as exemplified by one $\mathrm{CAB}$ officer, "since we are not actively working on these issues, we have not looked into whose responsibility it is. So, it's unclear to us, or at least to me" (respondent C). A desire for better coordination between units within the same organisation is expressed. Examples of general coordination on some aspects of climate change are evident in municipal planning, and it appears as if the cooperation in small municipalities works well without any specific routines. In the opinion of one municipal planner, however, "[...] although it sounds awful, [...] it is probably very much about the ability of the individual civil servants [per se] to speak for their cause. To convince [others] that this is an area that really needs to be addressed. If you cannot speak for your cause and present the arguments properly, then nothing will happen" (respondent R).

External networks around climate change in general exist to inspire and support most of the organisational work. Surprisingly, some interviewees were not aware of this, with one individual explaining that they were not part of any of these groups. Although a number of the networks are national, most are regional, ranging in scope from general networking between $\mathrm{CABs}$ to specific subjects, such as church $\mathrm{CH}$ or forestry. The degree of cooperation with external actors differs between the organisations. Other authorities were named in the interviews, including the three types studied here, but also consultants, insurance and construction companies, and in some cases national sector authorities, including the Swedish National Board of Housing, Building and Planning and the NHB. It is apparent from the interviews that the experienced level of support from the NHB has declined, "many CABs appreciated the expert knowledge at the NHB that you could call and ask about different things, but now this is not available" (respondent B). The contracting of expert consultants seems more common at municipalities than at CABs. Notably, none of the interviewees mentioned cooperation with universities. 


\subsection{Challenges}

A relatively coherent picture of perceived future challenges was conveyed by the interviewees, most of which revolved around insufficient personnel and financial resources. Only a few interviewees state that they have all the required competences in-house, whilst most others, including at the STA and municipalities, state the opposite: "Regarding culture, only consultants have the top competence" (respondent G), "[I] have an external monitoring of [...] climate change. Not so much $\mathrm{CH}$, where we have no real competence today" (respondent $\mathrm{O}$ ), "The city does not hesitate to outsource assignments to specialists when needed, [if] it is beyond our level of competence. If we need better knowledge [...] we buy it" (respondent R). None of the respondents commented on how the quality of these external services was evaluated. Financial resources are often mentioned by the interviewees, with none stating that funds were sufficient. One interviewee connected this to case processing time, "It is probably to a large extent the economy that decides, perhaps not [linked to] what action we take but at what pace we take them" (respondent L). Some interviewees were resigned to the lack of money being permanent, and instead focussed on the challenges this poses to the organisations. The appropriate level of ambition, both with respect to future climate scenarios and prioritisation between adaptive measures, was a prevalent challenge. An STA officer wondered "where are we aiming, what level of ambition are we aiming for? [...] Which RCP scenarios should we work with, 8.5 or 4.5 ? Should we aim 25 years ahead, should we aim 50 years forward? [...] Thus [...] in the end it is actually an issue of priority. If we don't have the money to fix everything, what should be addressed first?" (respondent F). A municipal planner further elaborated, "we will not be able to protect everything, save everything. I would say that will be the toughest priority challenge" (respondent O). One CAB interviewee highlighted the need of a "national declaration on which cultural values can be accepted to disappear into the sea [due to shore erosion], [...] or if there should be allocated resources for protection and so on. There are no systems for that either" (respondent $\mathrm{H}$ ). The question of who should prioritise, so that prioritisation is the same between authorities and other actors, was expressed by a TRA officer, "the biggest challenges are coordination, because there are many stakeholders, many who should be involved" (respondent F). Respondent E elaborates further, suggesting meeting such challenges using "[a] type of common risk and vulnerability analysis model where you can still enter [...] common criteria. [...]". They go on to explain that "[y]ou have Environmental Impact Assessments, but they are not always done the same way. I would like to see a regulation to ensure that weighting is done in the same way, or at least how to weight in order to make [the] evaluation more reasonable. [...] Then I think it is easier for the administrators to get an understanding of the complexity. Because that's the one we constantly deal with, complexity. [...] In the end, it's a trade-off. [...] But a type of template or type of surveying instrument where you can insert these criteria, you could weight them in some way".

\section{Discussion}

For more than two decades, increasing rates of climate change, and their increasing effects on society, have been politically relevant internationally. In this study, we investigated climaterelated activities in practice through the lens of institutional interplay, with a focus on $\mathrm{CH}$ and landscape in the context of transport infrastructure. Surprisingly, landscapes hardly feature at all in the national reports and interviews, an absence which has influenced the following 
discussion and conclusions. Initially, three research questions were asked, each of which is discussed below.

$\mathrm{CH}$ and climate change is perceived as an important issue by the interviewees, not least because legislation states that $\mathrm{CH}$ lies within the area of responsibility for their employers. However, work under this theme is clearly in its infancy, something reflected in the interviews through a general expression of surprise at the subject of this research project. The reviewed reports suggest that official information supporting this new area of work was perceived as lacking. An interpretation confirmed by several respondents who found it difficult to prioritise knowledge acquisition (Schön, 1983), much of which must be done in their spare time. Appropriate training has been identified as a human resource barrier with respect to climate change adaptation (Piggott-McKellar et al. 2019), but the communication and training of civil servants in new policy areas is complicated in Sweden by the relative independence of authorities. As our results show, if an activity is to function equally in different parts of a country and at different levels of government, there must be a level playing field in terms of knowledge. The dissemination of knowledge should therefore be of national interest if climate and environment goals are to be met, and enhanced climate change adaptation training has been promoted as a key solution for greater effectiveness (Yoseph-Paulus and Hindmarsh 2018; Piggott-McKellar et al. 2019). Such a national strategy was implemented in connection with the inauguration of the Environmental Code in 1999, when it replaced 15 environmental acts (Thews et al. 2017) and required Environmental Impact Assessments to be handled by many authorities involved in spatial planning. Special funds were set aside, and training was carried out by CABs, targeting all authorities, including those undertaking research.

The reports and interviews complement each other in terms of coverage of the climate threats described and the impacts that these can be expected to have, or have already had, on $\mathrm{CH}$. The NHB's pilot report [2] is clear and comprehensive, but surprisingly, the interviewed organisations have hardly begun to reflect upon the issues described. This is especially the case with respect to the road sectors' own $\mathrm{CH}$, although some interviewees have clearly begun to reflect more than their employers have. Water is a constantly recurring concern in the interviews, including increased humidity, rainfall and runoff, more floods - coastal and inland, and changing marine currents. This concern is mirrored in other areas of Northwestern Europe, and the UK has experienced increased flooding over the past decades (Blöschl et al. 2019), with both transport infrastructure and $\mathrm{CH}$ significantly impacted. In the UK, as in southern Sweden, coastal erosion is seen as one of the primary threats to $\mathrm{CH}$, and in Scotland, a crosssector (community, research, heritage management) effort for mapping, monitoring and excavating coastal sites has been in place since 2012 (SCAPE Trust 2012). Harkin et al. (2020) express the importance of coastal and maritime heritage, and its threatened status, in terms of marine transport and its connection to the global economy of the past. They also reflect on lost (flooded or eroded) landscapes, something which is relatively common in scientific literature, but missing from the organisational perspective of the reports and especially the interviews in this study. As in Sweden, there is a perceived gap between policy and actions, where "[m]uch legislation has been enacted to protect sites of historic interest, but these do not protect sites from natural processes" (Graham et al. 2017).

Matthews et al. (2007), in their overview of disaster planning in the archives, libraries and museums sector, reflect on the importance of international awareness and communications when working at the national level. Their emphasis on the importance of both international and cross-sector perspectives is something repeated in the scientific literature. Hambrecht and Rockman (2017) describe the USA National Parks Service's "four-pillar approach" to dealing 
with climate change (science, mitigation, adaptation and communication) from an international perspective. They also conclude the need for greater knowledge sharing between stakeholders internationally, as well as greater communication, new tools and resources for monitoring and dealing with the effects of climate change. Whilst community engagement, and the views of those directly affected by change, was beyond the scope of this project, it is clear from other countries that this would be a valuable angle for future studies in Sweden.

Although staff at the CAB and STA were aware of their organisations' climate coordination officers, this was not the case at the municipalities. This indicates uncertainty on the level of internal support available. All interviewees stated, in one form or another, that the $\mathrm{CH}$ program at their organisation was too old to include climate threats and it is clear that the identification of threats to $\mathrm{CH}$ has just begun at the organisations included in this study. A national strategy for climate change-orientated $\mathrm{CH}$ and landscape planning also appears to be lacking, and, moreover, there are currently no clear routines for prioritisation, a problem highlighted as a barrier to planning (Uittenbroek 2016; Fatorić and Biesbroek 2020). This applies to all of the administrative levels studied, with almost all climate-related work being undertaken reactively and competing for time with existing tasks which are required by legislation. Outside of $\mathrm{CH}$ divisions, $\mathrm{CH}$ is usually not a primary concern, although there may be unintended positive effects when remedial work encompasses it. Whilst the lack of standardised guidelines on how to handle climate risks, and the need to act on a reactive basis, is clearly comprehended as problems by the interviewees, the rapid nature of climate change and extreme events may actually necessitate a flexible, and perhaps in fact, reactive, form of management. The latter is uncommon in government structures, and organisations with experience of working in such conditions may be surprisingly well prepared for the future.

In the interviews, the NHB are repeatedly criticised for inaction, insufficient support, or failure to undertake what interviewees believe should be the board's assignments and tasks. This may be due to unclear roles (Storbjörk 2007) and mandates (Antonson et al. 2016), but most likely it indicates poor communication between the organisations, where experiences do not match the potential resources available. This type of deficient interplay between external organisations (Young 2002) can also be found within the studied authorities. Different authority departments do not always inform each other or exchange experience (c.f. Antonson et al. 2016), and in some cases in-house networks are ceasing to exist. There are some climate or $\mathrm{CH}$ networks between $\mathrm{CABs}$ apparently work well. These networks, however, do not include actors outside the CABs, such as consultancies and municipalities. There appears to be a need for an adaptive management network (Berkes 2009; c.f. Corfee-Morlot et al. 2011) for sharing knowledge, data (Buckland et al. 2018) and experiences within the field of climate and $\mathrm{CH}$ on a national level (c.f. Granberg and Elander 2007; Gustavsson et al. 2009). Such networks have been successfully implemented for other current issues, such as planning for electric vehicles (Antonson and Carlson 2018), where a cross-scale multi-level network exists for all major actors (consultancies, enterprises, NGOs, and local, regional and national authorities).

Many interviewees expressed frustration at the lack of time available for forward thinking. They also experienced limitations in the time and resources available for carrying out strategically planned work on the management of $\mathrm{CH}$ with respect to future climate change. Sufficient resources, both monetary and personnel, are barriers to a smooth planning process (Bedsworth and Hanak 2013; Ziervogel and Parnell 2014). However, Fatorić and Biesbroek (2020) found that institutional and technical barriers 
dominated over financial barriers in the Netherlands. Granberg and Elander (2007, p. 546) touched upon a possible reason for the perceived lack of resources, raising the more general question of how municipalities prioritise with respect to territory and citizens, and "not just particular categories" in which some actions are executed at the expense of others. In the late 1980s, Swedish municipalities gained a high degree of selfdetermination (called the municipal planning monopoly in Swedish), and state steering in municipal planning has not always been appreciated (Storbjörk and Hedrén 2011). Regional authorities, which represent the state, have raised concerns over municipal priorities, and their ability to plan with respect to the bigger picture (Antonson et al. 2016).

In the long run, if further resources are not provided for facilitating the evaluation of threats and vulnerabilities, or for the creation of national guidelines, prioritisation will continue to be based on experience. The Swedish Historic Environment Act is not applicable when weather destroys cultural resources, only when people do (c.f. Graham et al. 2017). Hence, adaptation measures for the prevention or mitigation of climate-related damage may not necessarily be based on legislation. It is more likely that prioritisation will be based on available state finances, or as one interviewee put it, "we will not be able to protect everything". This clearly indicates that at least some interviewees experience the area as underfunded (Hall et al. 2016; c.f. Rockman and Hritz 2020). As climate change impacts become increasingly prevalent, consideration of their effects on $\mathrm{CH}$ and landscape will probably become encompassed in normal planning practice. This parallels the development of environmental impact assessments during the 1980s, which expanded from covering only toxic substances to include landscapes (Antonson 2008). On the evidence of this study, however, legislation has a long way to go before the organisations are provided with a suitably encompassing legal framework (c.f. Sesana et al. 2019). How consideration of the cultural landscape, as distinct from or integral to sites and monuments, should become integrated into the $\mathrm{CH}$ climate assessment process is open to debate. There is considerable variation on this theme internationally (see Fairclough et al. 2018), but the limited attention landscapes receive in the interviews and reports studied here suggests that more explicit guidelines for landscape scale assessments could be beneficial to a more holistic approach.

An alternative to changing legislation, in order to create a national consensus, is the creation of a handbook (manual) or an ISO-standard (or the national equivalent, SIS) (c.f. Sesana et al. 2018). Whilst there are a number of national handbooks available, these cover only limited aspects of climate change and rarely focus on $\mathrm{CH}$. This could include material and methods collated from other documents, such as the high water planning guide (SFS 2009), examples of good practice from Swedish authorities and take advantage of the international equivalents (e.g. Michalski and Pedersoli Jr 2016). Benefits would include the following: processes and workflows (e.g. data sources and GIS) can be described; ambiguity of interpretation can be reduced (especially important at $\mathrm{CABs}$ ); and the procurement process can be simplified through reference to the manual (writing the procurement, assessing the tenders, quality assurance).

Another experienced barrier to a progressive planning process is the lack of tools to identify climate-threatened $\mathrm{CH}$. So far, the authorities have mainly worked with simple, overlapping layer-based GIS techniques to evaluate how future floods might affect $\mathrm{CH}$. These are often deployed as overlays in existing management systems, and whilst useful, provide only static indications of the known sites most likely to be impacted within the geographical areas of a modelled risk. This provides no capacity for predicting the nature and extent of any potential impacts on a particular site, the probability of impacts on undiscovered archaeological sites, 
modelling indirect effects (water table changes, landslides, etc.), or assessing risks to the cultural landscape. Flood frequency maps (e.g. 50/100 year floods) may help prioritise adaptation measures on the probability of a site being flooded, but they give no indication of the value of the sites or the susceptibility of a particular site type to a particular type of damage. There is thus a need for more advanced, $\mathrm{CH}$-orientated tools, giving administrators access to up to date scientific assessment methods for evaluating the implications of climate change for any $\mathrm{CH}$ site.

Neither the reports nor the interviews provide information on how the government, acting through the authorities, plans to prioritise for climate change impacts on $\mathrm{CH}$. Although it has yet to have become a problem between authorities in Sweden, different approaches and associated costs can lead to conflict (Pløger 2004). Without a national strategy for prioritisation, different authorities are driven to reactive solutions to immediate risks and ad hoc strategies for mitigating future climate change. There is a risk that when such solutions are repeated, they become standard practice, differing between organisations with their own goals and areas of expertise. It is therefore important that a common strategy is developed as soon as possible, with responsibility at the highest level. Some respondents touched upon the delicate question in this context, of with whom the responsibility should lie? The ultimate responsibility falls, naturally, on the elected government, and under this every relevant authority whose area of activity is in some way affected by climate change. In Sweden, policies must be implemented in a governmental structure which is characterised by small ministries and large sector authorities with large delegated responsibilities, as well as highly autonomous municipalities (Ladner, 2017). Currently, at national level, the NHB is responsible for $\mathrm{CH}$, and the STA is responsible for transport infrastructure; the $21 \mathrm{CABs}$ are responsible for all policy areas regarding spatial planning at the regional level. At the same time, the STA and nine other sector authorities have been assigned the responsibility for managing $\mathrm{CH}$ within the framework of their operations. The picture that emerges is undeniably fragmented from an external perspective, and this scattered responsibility was perceived as muddled and cumbersome by several interviewees.

In a rapidly advancing field, centralising responsibility for climate change impacts on $\mathrm{CH}$ would require that the organisation in question had access to, and made use of, state of the art knowledge from the research community (i.e. universities). It would probably also require evaluation or auditing mechanisms, including cross-sector expert groups, to ensure that conclusions from current research were practically implemented into policy. Several actors would need to be integrated within the framework of a cross-sectoral network with representatives from all sectors and levels of society, including local, regional and national authorities, consulting companies and universities. In order to be effective at the national level, the convener of the network should ideally be a state sector authority, possibly the NHB, to ensure that a national strategy is suitably authored and implemented.

We began this paper by highlighting Sweden's progressive environmental and climate work in the 1970s and subsequent decades. Sweden has also been well known for its social engineering and welfare, where the country has been placed high in international rankings. This picture of this successful country does not correspond with the view presented by the interviews, where both financial and personnel resources are considered insufficient, and readiness to manage $\mathrm{CH}$ in the context of climate change does not seem high. Further studies are needed, however, to investigate whether Sweden's decentralisation of planning practices has led to a fragmentation of processes and an increased degree of interplay, both horizontally and vertically. 


\section{Conclusion}

Our three case studies show that, despite its high world ranking in progress on SDGs, Sweden is not particularly well prepared for dealing with climate change impacts on $\mathrm{CH}$ and landscape. The interviews in particular have provided new insights into contrasts between the public or research perception of what could or should be done to protect $\mathrm{CH}$ from climate change, and the reality of the planning activities of different government actors. In reviewing background literature for this paper, it is our impression that other countries, including Italy and the UK (and especially Scotland), have come much further (see Adger et al. (2018) for examples), and there are clearly lessons to be learned from international cooperation (Challinor et al. 2018). With the support of international planning research, we have identified several barriers that hamper smooth planning. Our investigation has resulted in a number of recommendations to overcome these, outlined below, which may enhance planning practice for a wider international group of archaeologists and heritage planners:

1. Roles and mandates must be clarified by the highest national authorities working on climate change, $\mathrm{CH}$ and landscape and transport infrastructure. Otherwise, there is a risk of planning inconsistency throughout the country.

2. Effective planning requires clarity on the types of $\mathrm{CH}$, including landscapes, which should be adapted (e.g. protected or documented) to a changing climate. The establishment of such prioritisation should be cross-sectoral and include representatives from all major stakeholders, including the general public.

3. Development of standardised methods for identifying threatened $\mathrm{CH}$ and landscape is important not only for enabling reliable national overviews, but also for ensuring the procurement of tools and adaptation measures becomes more effective, convenient and assessable. The development of more accessible advanced GIS tools for heritage risk assessment should be part of this.

4. The creation of a comprehensive handbook or best-practice manual is crucial for an issue handled by many actors, many of which lack detailed knowledge of $\mathrm{CH}$ and climate change. Such a resource would be useful for both decision-making authorities and consulting companies, and act as a reference assessing the solvency of climate impact assessments. It would also be useful for international comparisons, and provide national details which are often lacking in international overviews or scientific publications.

5. Where not already operating, we recommend the initiation and support of national crosssector multi-level networks for all major actors within the field of climate change and $\mathrm{CH}$. This should be under the auspices of the designated state sector authority, and will be important for knowledge building and experience sharing. The network should cover all types of questions, both strategic and practical, as well as those concerning threats and adaptation solutions.

Placeholder TextPlaceholder Text 
Supplementary Information The online version contains supplementary material available at https://doi.org/ 10.1007/s10584-021-03115-y.

Acknowledgements Karin Fröjmark Svanström, Camilla Eriksson and Stina Ekberg at KMV forum AB participated in the compilation of national reports. Samuel Ericson at the Environmental Archaeology Lab, Umeå University, also provided feedback on an earlier version of this manuscript. We would like to thank all interviewees who have volunteered their time and the four anonymous reviewers for their constructive comments.

Availability of data and material The interview transcripts will not be made publicly available due to our understanding of the GDPR-legislation protecting the identities and opinions of the interview subjects, as well as the anonymity requirement requested by some of the interviewees. The interviews were undertaken in Swedish, with the citations used in the text translated by the second author (native British speaking) and anonymised to protect the identity of the individual and the organisation at which they worked.

Code availability Not applicable

Author contribution The first author has, beside contributed extensively to the text regarding planning processes, conducted all interviews and participated in the compilation of national reports together with Karin Fröjmark Svanström, Camilla Eriksson and Stina Ekberg at KMV forum AB. Philip Buckland contributed extensively to the text and provided the international research context. Roger Nyqvist contributed to the text and provided additional information on the administrative context.

Funding This article is part of the research project "Cultural Heritages and Landscapes in a Changing Climate. Climate adaptation of the Swedish Transport Administration's area of responsibility for robust planning for increased environmental achievement (Kulturmiljöer och landskap i ett förändrat klimat. Klimatanpassning av Trafikverkets verksamheter för en robust planering för ökad miljömålsuppfyllelse)" and has been financed by the Swedish Transport Administration's Research and Development grant (number Dnr: TRV 2018/118237).

\section{Declarations}

Conflict of interest The authors declare no competing interests.

Open Access This article is licensed under a Creative Commons Attribution 4.0 International License, which permits use, sharing, adaptation, distribution and reproduction in any medium or format, as long as you give appropriate credit to the original author(s) and the source, provide a link to the Creative Commons licence, and indicate if changes were made. The images or other third party material in this article are included in the article's Creative Commons licence, unless indicated otherwise in a credit line to the material. If material is not included in the article's Creative Commons licence and your intended use is not permitted by statutory regulation or exceeds the permitted use, you will need to obtain permission directly from the copyright holder. To view a copy of this licence, visit http://creativecommons.org/licenses/by/4.0/.

\section{References}

Adger WN, Brown I, Surminski S (2018) Advances in risk assessment for climate change adaptation policy. Phil Trans R Soc A 376:20180106

Antonson H (2008) Landskap i infrastrukturplaneringen - styrdokumentens påverkan. In: Brusman M, Friberg T, Summerton J (eds) Resande, planering och makt. Arkiv förlag, Lund, pp 105-120

Antonson H, Carlson A (2018) Spatial planning and electric vehicles. A qualitative case study of horizontal and vertical organisational interplay in southern Sweden. J Environ Plan Manag 61:1340-1362

Antonson H, Storbjörk S, Hjerpe M, Isaksson K (2016) Negotiating climate change responses: regional and local perspectives on transport and coastal zone planning in South Sweden. Land Use Policy 52:297-305 
Baxter J, Eyles J (1997) Evaluating qualitative research in social geography: establishing 'rigour' in interview analysis. Trans Inst Br Geogr 22:505-525

Bedsworth LW, Hanak E (2013) Climate policy at the local level: insights from California. Glob Environ Chang 23:664-677

Berkes F (2009) Evolution of co-management: role of knowledge generation, bridging organizations and social learning. J Environ Manag 90:1692-1702

Blöschl G, Hall J, Viglione A et al (2019) Changing climate both increases and decreases European river floods. Nature 573:108-111

Bryman A, Teevan J (2005) Chapter 13: qualitative data analysis. In Social research methods, 282-310. London: Oxford University Press

Buckland PI, Nyqvist R, Alexander B, Palsson G. Eriksson, S (2018) The Swedish Transport Administration's toolbox and its potential in archaeological and CH survey. MAL report no. 2018-001. Umeå University

Challinor AJ, Adger WN, Benton TG, Conway D, Joshi M, Frame D (2018) Transmission of climate risks across sectors and borders. Phil Trans R Soc A 376(2121):20170301

Corfee-Morlot J, Cochran I, Hallegatte S, Teasdale P-J (2011) Multilevel risk governance and urban adaptation policy. Clim Chang 104:169-197

Creswell JW (2014) Research design. Qualitative, quantitative and mixed methods approaches. Sage, Thousand Oaks, California

European Commission (2016) Communication from the Commission to the European Parliament, the Council, the European Economic and Social Committee and the Committee of the Regions. A European Strategy for Low-Emission Mobility. COM (2016) 501 final

Fairclough G, Herlin IS, Swanwick C (2018) Routledge handbook of landscape character assessment: current approaches to characterisation and assessment. Routledge

Fatorić S, Biesbroek R (2020) Adapting cultural heritage to climate change impacts in the Netherlands: barriers, interdependencies, and strategies for overcoming them. Clim Chang 162:301-320

Fatorić S, Seekamp E (2017) Are cultural heritage and resources threatened by climate change? A systematic literature review. Clim Chang 142:227-254

Foster G, Kreinin H (2020) A review of environmental impact indicators of CH buildings: a circular economy perspective. Environ Res Lett 15:043003

Gifford R (2014) Environmental psychology matters. Annu Rev Psychol 65:541-579

Government (2018) Nationell strategi för klimatanpassning. prop. 2017/18:163. Regeringskansliet. Accessed 21 January 2020. http://www.regeringen.se/rattsdokument/proposition/2018/03/prop.-201718163/

Graham E, Hambly J, Dawson T (2017) Learning from loss: eroding coastal heritage in Scotland. Humanities 6: 87

Granberg M, Elander I (2007) Local governance and climate change: reflections on the Swedish experience. Local Environ 12:537-548

Gustavsson E, Elander I, Lundmark M (2009) Multilevel governance, networking cities, and the geography of climate-change mitigation: two Swedish examples. Environ Plann C 27:59-74

Hall CM, Ram Y (2016) Heritage in the intergovernmental panel on climate change assessment reports: a lexical assessment. J Herit Tour 11:96-104

Hall CM, Baird T, James M, Ram Y (2016) Climate change and cultural heritage: conservation and heritage tourism in the Anthropocene. J Herit Tour 11:10-24

Hambrecht G, Rockman M (2017) International approaches to climate change and cultural heritage. Am Antiq 82:627-641

Harkin D, Davies M, Hyslop E, Fluck H, Wiggins M, Merritt O, Barker L, Deery M, McNeary R, Westley K (2020) Impacts of climate change on cultural heritage. MCCIP Sci Rev 2020:616-641

Hollesen J, Matthiesen H, Fenger-Nielsen R, Abermann J, Westergaard-Nielsen A, Elberling B (2019) Predicting the loss of organic archaeological deposits at a regional scale in Greenland. Sci Rep 9:90-97

Kohler TA, Rockman M (2020) The IPCC: a primer for archaeologists. Am Antiq 85:627-651

Kvale S (1994) Ten standard objections to qualitative research interviews. J Phenomenol Psychol 25:147-173

Lewicka M (2011) Place attachment: how far have we come in the last 40 years? J Environ Psychol 31:207-230

Lipsky M (1980) Street level bureaucracy: dilemmas of the individual in public services. Russell Sage Foundation, New York

Matthews G, Smith Y, Knowles G (2007) Disaster management in archives, libraries and museums: an international overview. Alexandria, J Nat Int Libr Inf Issues 19:1-22

Mees H, Driessen P, Runhaar H, Stamatelos J (2013) Who governs climate adaptation? Getting green roofs for stormwater retention off the ground. Environ Plan Manag 56(6):802-825

Mézáros S, Antonson H (2020) Struggling, settling, solutions: a qualitative study of landscape protection in motorway planning. Transp Res D Transp Environ 82:1-20 
Michalski S, Pedersoli JL Jr (2016) The ABC method: a risk management approach to the preservation of $\mathrm{CH}$. Canadian Conservation Institute, Ottawa

Piggott-McKellar AE, McNamara KE, Nunn PD, Watson JEM (2019) What are the barriers to successful community-based climate change adaptation? A review of grey literature. Local Environ 24:374-390

Pløger J (2004) Strife: urban planning and antagonism. Plan Theory 3:71-92

Robinson OC (2014) Sampling in interview-based qualitative research: a theoretical and practical guide. Qual Res Psychol 11:25-41

Rockman M, Hritz C (2020) Expanding use of archaeology in climate change response by changing its social environment. Proc Natl Acad Sci U S A 117:8295-8302

Sachs J, Schmidt-Traub G, Kroll C, Lafortune G, Fuller G (2019) Sustainable Development Report 2019. Transformations to achieve the sustainable development goals. Bertelsmann Stiftung, New York

Sandkjaer Hanssen GP, Mydske K, Dahle E (2013) Multilevel coordination of climate change adaptation: by national hierarchical steering or by regional network governance? Local Environ 18:869-887

SCAPE Trust (2012) Scotland's coastal heritage at risk project. Accessed 23 February 2020. http://www.scharp. co.uk/

Sesana E, Gagnon A, Bertolin C, Hughes J (2018) Adapting cultural heritage to climate change risks: perspectives of cultural heritage experts in Europe. Geosciences 8:305

Sesana E, Bertolin C, Gagnon AS, Hughes JJ (2019) Mitigating climate change in the cultural built heritage sector. Climate 7:90

SFS (2009) Förordning om översvämningsrisker. Svensk författningssamling SFS 2009:956

Shirvani Dastgerdi A, Sargolini M, Pierantoni I (2019) Climate change challenges to existing cultural heritage policy. Sustainability 11:5227

SMHI (2020) The Swedish portal for climate change adaptation. Swedish National Knowledge Centre for Climate Change Adaptation. Accessed 14 June 2020. http://www.klimatanpassning.se/en/

SOU (2000) Förslag till Svensk Klimatstrategi - Klimatkommitténs betänkande. Statens offentliga utredningar 2000:23

STA (2014) Strategi för klimatanpassning. TDOK 2014:0882. Swedish Transport Administration

Storbjörk S (2007) Governing climate adaptation in the local arena: challenges of risk-management and planning in Sweden. Local Environ 12:457-469

Storbjörk S, Hedrén J (2011) Institutional capacity-building for targeting sea level rise in the climate adaptation of Swedish coastal zone management. Lessons from Coastby. Ocean Coast Manag 54:265-273

Thews B, Höjding, P Jansson B (2017) Swedish Environmental Law: An introduction to the Swedish legal system for environmental protection. Swedish Environmental Protection Agency, Rapport 6790, Sweden

Uittenbroek CJ (2016) From policy document to implementation: organizational routines as possible barriers to mainstreaming climate adaptation. J Environ Policy Plan 18:161-176

Yoseph-Paulus R, Hindmarsh R (2018) Addressing inadequacies of sectoral coordination and local capacity building in Indonesia for effective climate change adaptation. Clim Dev 10:35-48

Young OR (2002) Institutional interplay: the environmental consequences of cross-scale interactions. In: National Research Council: The Drama of the Commons. The National Academies Press, Washington, DC

Ziervogel G, Parnell S (2014) Chapter 3: Tackling Barriers to Climate Change Adaptation in South African Coastal Cities. In BC. Glavovic and GP. Smith, Adapting to Climate Change: Lessons from Natural Hazards Planning, 57-73

Publisher's note Springer Nature remains neutral with regard to jurisdictional claims in published maps and institutional affiliations. 